\title{
PESQUISA ACADÊMICA E MOVIMENTO SURDO: A SOBREPOSIÇÁO DE UM FAZER ACADÊMICO E DE UM FAZER ATIVISTA NO FIO DO DISCURSO
}

\section{ACADEMIC RESEARCH AND DEAF MOVEMENT: THE OVERLAP OF AN ACADEMIC PROCEDURE AND AN ACTIVIST PROCEDURE WITHIN THE SCOPE OF DISCOURSE}

\author{
Maria Clara Maciel de Araújo Ribeiro \\ Universidade Estadual de Montes Claros, UNIMONTES, Montes Claros, MG, Brasil \\ Glaucia Muniz Proença Lara \\ Universidade Federal de Minas Gerais, UFMG, Belo Horizonte, MG, Brasil
}

Resumo: À luz da Análise do Discurso de orientação francesa (MAINGUENEAU, 2005, 2008), o presente artigo analisa a introdução de uma tese de doutorado produzida por uma surda ativista no movimento surdo, com o intuito de investigar como a tensão constitutiva entre um fazer acadêmico (a produção de uma tese) e um fazer militante (o engajamento em uma luta social) se resolve no fio do discurso de uma pesquisa considerada engajada. Os resultados mostram que a relaçáo de ativismo é explicitamente relatada pela locutora, que projeta sobre si um ethos híbrido, que mescla feixes constitutivos tanto da imagem de uma pesquisadora com poder de discernimento quanto de uma ativista engajada, com predomínio da segunda imagem.

Palavras-chave: surdos; ativismo social; movimento surdo; pesquisa acadêmica; discurso acadêmico.

Abstract: In the light of French Discourse Analysis (MAINGUENEAU, 2005, 2008), this text analyses the introduction of a doctoral thesis, produced by a deaf woman, who is also an activist in the deaf movement, in order to investigate how the tension between an academic procedure (the production of a thesis) and a militant procedure (the engagement in a social cause) is solved within the scope of a discourse in a so-called engaged research. The results show that the activist procedure is explicitly reported by the author, who projects on herself a hybrid ethos that mixes two constitutive aspects: the image of a researcher with discerning power and that of an engaged activist, with predominance of the second image.

Keywords: deaf; social activism; deaf movement, academic research; academic discourse. 


\section{Primeiras palavras}

Os mais admiráveis pensadores da comunidade acadêmica não separam seu trabalho de suas vidas. Parecem levá-los ambos a sério demais para admitir tal dissociação, e querem usar uma coisa para o enriquecimento da outra (MILLS, 1998, p. 27).

As duas últimas décadas foram decisivas para as comunidades surdas brasileiras. Uma série de conquistas, como a legalização da Libras, a profissionalização do intérprete e o acesso de surdos ao Ensino Superior, reconfiguraram relaçóes de poder entre surdos e ouvintes. Discursos que reconhecem e valorizam as especificidades linguísticas e culturais dos surdos começaram a ser difundidos a ponto de concorrerem com o discurso médico sobre a surdez. Em nosso ver, as transformaçóes ocorridas no campo do direito e da vida social dos surdos são tributárias, em boa medida, da atuação e do fortalecimento do Movimento Surdo brasileiro, que formou lideranças, fidelizou adeptos e adentrou a universidade como estratégia de legitimação.

$\mathrm{Na}$ academia, o movimento surdo atua fazendo sobrepor pesquisa acadêmica e ativismo social - para alguns, uma atividade insolente a ser evitada ${ }^{1}$; para outros, uma proposta que lança luz sobre os excluídos e questiona a colonialidade do poder, dando mostras de que um paradigma de racionalidade científica emergente (que questiona o paradigma dominante) se configura cada vez mais nitidamente. No paradigma emergente, como sustenta Santos (2009, p. 30), "o conhecimento é prudente e visa a uma vida decente", pois elege a comunidade, a participação e a solidariedade como princípios. Sua racionalidade torna-se estético-expressiva, e o conhecimento ora regulatório transforma-se em conhecimento emancipatório, que se mostra responsável (ético) e político (participativo).

Neste texto, interessamo-nos, notadamente, por um fenômeno que compóe o chamado paradigma emergente: o entrelaçamento da agenda de lutas do Movimento Surdo com a academia, o que resulta na produçáo de pesquisas engajadas que impóem aos sujeitos produtores um esforço de articulação de papéis discursivos, nem sempre facilmente conciliáveis. Referimo-nos a casos em que uma liderança surda realiza uma pesquisa acadêmica que é permeada pela trajetória de lutas do Movimento Surdo, evidenciando conflitos e tensóes discursivas entre duas facetas de um mesmo sujeito: uma que responde a uma dada tradiçáo acadêmica, outra que

${ }^{1}$ Referimo-nos aos adeptos do paradigma de racionalidade científica dominante, que só acredita na produção de conhecimento pretensamente neutro e deslocado de seus produtores. 
responde a um percurso de lutas sociais.

Partindo dessas considerações, discutimos, neste artigo, como a tensão constitutiva entre o sujeito surdo pesquisador e o sujeito surdo ativista social se resolve no plano discursivo de uma tese de doutorado sobre a temática da surdez, produzida por uma surda considerada, à época de realizaçáo da tese, líder no âmbito do Movimento Surdo. Assim, perguntamos em que medida a relação de engajamento é assumida ou negada pela locutora da tese? ${ }^{2}$ Como essa relação é justificada (ou silenciada) e quais são as estratégias requisitadas para legitimar a pesquisa no âmbito da academia? Para responder a essas questóes, partimos da Análise do Discurso (AD) de orientação francesa (MAINGUENEAU, 2005, 2008) e analisamos, especificamente, a introduçáo de uma tese de doutorado em Educação, produzida por uma surda ativista.

Nas próximas seçóes, discutiremos brevemente o deslocamento epistêmico que o sintagma "surdo pesquisador" impóe à memória discursiva, caracterizando surdos como intelectuais específicos. Em seguida, a introdução da referida tese será analisada, com vistas a responder às questóes propostas. Esclarecemos que, neste artigo, apresentaremos o dispositivo teórico entremeado à própria análise, sobretudo por meio do recurso à explicitação de conceitos em nota de rodapé. Assim, reduziremos o aparato teórico àquilo que é indispensável à compreensão da análise e, para redimir eventuais faltas, remetemos o leitor a Ribeiro (2012), trabalho no qual se encontra a nossa teoria de base suficientemente delineada.

\section{Produçáo de conhecimentos por intelectuais surdos}

A história mostra-nos que, durante séculos, pessoas surdas foram consideradas indesejáveis e mesmo invisibilizadas socialmente. A partir da década de 1960, no entanto, com a corrida pela descrição das línguas de sinais em várias partes do mundo, surdos passam a ser também objeto de pesquisa. A academia começa, entáo, a pesquisar inúmeros traços constitutivos do que se considera a experiência de vida de surdos: as línguas de sinais e seus processos de aquisição, ensino e tradução/interpretação;

${ }^{2} \mathrm{O}$ conceito de locutor está sendo mobilizado na perspectiva de Ducrot (1987, p. 187-188), que o considera como um ser do discurso que é responsável pela enunciação. Nesse sentido, o uso que fazemos de "locutora" ou simplesmente "locutora" aqui e em outras partes deste trabalho (sobretudo, na seção dedicada à análise) vem ressaltar nosso interesse pelo "ser do discurso" envolvido na produçấo de uma tese. 
os processos de educação de surdos; as culturas e identidades fundadas na surdez etc. Os surdos passam, assim, da invisibilidade social à visibilidade parcial, tanto pelo viés da academia, que os toma como objeto de pesquisa, quanto pelo viés de movimentos sociais de surdos, que vocalizam lideranças e reivindicam, para o grupo, espaços e direitos sociais.

Movimentos Sociais, segundo Rangel (2010), desempenham um importante papel no processo de expressão e participação democrática na sociedade, pois desencadeiam debates que sustentam e tornam relevante a reivindicação de direitos - além de estimular a construção da cidadania, dando visibilidade e incentivando a uma resolução de impasses que constituem obstáculos à vida cidadã.

Nessa perspectiva, o Movimento Surdo é responsável pela presença, nos surdos, de uma identidade surda política e consciente de si mesma (PERLIN, 2003). É o Movimento Surdo que politiza as comunidades surdas e que discute temas de interesse do grupo, pautando a agenda de lutas e reivindicaçóes de toda uma geração. É no movimento ainda que a política da identidade surda é gestada e que os surdos se fortalecem para guardar as fronteiras de uma alteridade a ser preservada, resistindo coletivamente ao "poder administrativo", historicamente exercido pelos ouvintes sobre eles (PERLIN, 2003).

Parece-nos que boa parte da credibilidade conferida atualmente ao Movimento Surdo pode ser atribuída ao alto grau de formaçáo acadêmica de parte de seus líderes, surdos graduados, mestre ou doutores em alguma área das Humanidades. Tudo indica que o sistema de imagens sociais de nossa sociedade determina que a reivindicação de um surdo, por si só, pode não ser digna de fé, mas que a reivindicação de um grupo de graduados, mestres ou doutores, ainda que surdos, se torna credível.

A partir daí, dotados de consciência política e de saberes acadêmicos, pesquisadores surdos olham para o passado (e para uma ponta do presente) e concluem que a história dos surdos foi marcada pelo etnocentrismo e pela colonizaçáo dos surdos pelos ouvintes (STROBEL, 2008). Percebem, então, que a condição de colonizados encobriu por muito tempo não apenas riquezas linguísticas e culturais das comunidades surdas, mas, sobretudo, a possibilidade de desenvolvimento desses sujeitos, que tiveram o seu espaço de atuação determinado e limitado pelo olhar restritivo que lhes fora imputado.

Logo, sujeitos que foram marcados historicamente pelo estigma da deficiência ingressam hoje na pós-graduação stricto sensu, provocando um deslocamento epstemológico que os move de objetos pesquisados a sujeitos da 
pesquisa. $\mathrm{Na}$ academia, surdos tematizam a sua comunidade na produção de pesquisas que se mostram engajadas objetivando também edificar uma nova imagem de si e dos seus pelo viés do conhecimento acadêmico. Escrevem, assim, por sobre o passado a visão libertadora do presente, reafirmando que a produção de conhecimento é um ato revestido de política.

De maneira geral, na pós-graduação, surdos discutem problemas relacionados à sua própria língua, educação e cultura. Discutem por uma ótica inovadora porque interna. Não se trata mais do ponto de vista do outro sobre o "dominado", mas das proposiçóes e visóes que, nascidas em meio à dominação, derivam de vivências conhecidas na pele. Por essa razão, sujeito e objeto, nas pesquisas empreendidas por surdos, não encarnam instâncias neutras e distantes, mas continuidades de uma mesma entidade (RIBEIRO, 2012).

Vemos, assim, em boa parcela das pesquisas produzidas por surdos, a impossibilidade de o sujeito da pesquisa exilar-se do sujeito que milita em uma causa social própria, de tal maneira que duas vozes podem ser percebidas nas referidas pesquisas: a do sujeito que pesquisa, gere e administra um fazer acadêmico, com as normas e coerçóes próprias a esse gênero textual e ao seu lugar institucional, e a do sujeito surdo que se envolve com os anseios e posicionamentos relativos à agenda de reivindicaçóes de um fazer ativista social (RIBEIRO, 2012). Ambas as vozes retratam, pois, a expressão de uma dada intelectualidade, a saber, a intelectualidade surda brasileira.

Surdos envolvidos tanto acadêmica quanto socialmente com a agenda de lutas do movimento surdo podem ser considerados intelectuais específicos, no sentido que Foucault (2004) atribui à expressão. Ao distinguir o intelectual universal, representante de uma consciência coletiva voltada para as questôes das massas, do intelectual específico, que se constrói e se sustenta como membro de um grupo específico para o qual volta sua atenção, Foucault (2004, p. 13) adverte que "é preciso pensar os problemas políticos dos intelectuais não em termos de 'ciência/ideologia', mas em termos de 'verdade/poder"'.

O intelectual específico se levanta, em geral, contra um sistema de poder hegemonicamente constituído e questiona um regime de verdade, ao mesmo tempo em que busca instituir outro. Surdos pesquisadores, enquanto intelectuais específicos, questionam, sobretudo, a representação da Libras e as estereotipias socialmente construídas sobre o ser surdo, assim como os modelos educacionais forjados pelos ouvintes para os surdos. Intelectuais específicos são, pois, considerados líderes representativos de 
uma determinada coletividade: se um dado sujeito ostenta defesas em nome próprio, afirma Deleuze (2006), é porque representa certa coletividade, um público específico: "quem fala e age? Sempre uma multiplicidade, mesmo que seja na pessoa que fala ou age. Nós somos todos pequenos grupos", garante o autor em conversa com Foucault (2004, p. 70).

Nessa perspectiva, autores surdos, como Rezende e Rezende Jr. (2007), defendem que, ao contrário do que os ouvintes historicamente fizeram (e ainda fazem) com os surdos - imposição linguística, cultural e educacional -, intelectuais surdos sediados na academia não exigem posturas ou impóem sua vontade política ao padrão de vida ouvinte, pois não tentam fazer prevalecer o seu regime de verdade sobre outro(s). Ao contrário, afirmam que intelectuais surdos analisam, principalmente, os espaços e acontecimentos que os cercam e os envolvem, fazendo dissipar conceitos ultrapassados e apresentando problematizaçóes outras, porque concebidas a partir de uma ótica interna.

Mas os intelectuais surdos sediados na academia não inovam apenas por se comprometerem com a sua comunidade de origem, desencadeando a produçáo de um conhecimento voltado para a promoçáo imediata de seu grupo sociocultural, mas também por se envolverem em atividades acadêmicas articuladas por sujeitos que, "ao desenvolverem suas pesquisas, privilegiam a parceria 'com' os movimentos sociais e extrapolam a tendência ainda hegemônica no campo das ciências humanas e sociais de produzir conhecimento 'sobre' os movimentos e os seus sujeitos" (GOMES, 2010, p. 494, grifos nossos).

É provável que o campo da educação, juntamente com a sociologia, seja uma das áreas do conhecimento em que a inserção de intelectuais específicos (surdos, negros, homossexuais, feministas...) se faça mais presente e visível. Como é de se esperar - e como informa a autora -, esses sujeitos

[...] se configuram não só como pesquisadores que atuam no meio acadêmico. Eles produzem conhecimento e localizam-se no campo científico. São intelectuais, mas um outro tipo de intelectual, pois produzem um conhecimento que tem como objetivo dar visibilidade a subjetividades, desigualdades, silenciamentos e omissóes em relaçáo a determinados grupos [...] e suas vivências. Para tal, configuram-se como um coletivo, organizamse e criam associaçóes científicas a fim de mapear, problematizar, analisar e produzir conhecimento (GOMES, 2010, p. 495).

É justamente aí que se enquadram os surdos intelectuais. E, como se 
vê, eles não são os únicos. A autora citada, por exemplo, trata especificamente da atividade acadêmica de negros intelectuais, embora a reflexão que tece sirva também para o caso dos surdos, uma vez que o que se discute aqui é a produçáo de conhecimento politicamente (auto)posicionado.

Nessa perspectiva, ao tematizar questóes surdas na academia, tais sujeitos já não produzem um conhecimento pautado pelo olhar do outro, mas pelo olhar endógeno, crítico e analítico do próprio surdo como pesquisador da temática surda. Não se trata mais de um olhar dito neutro e distante sobre fenômenos sociolinguísticos e educacionais que envolvam surdos, mas, sim, de uma análise e de uma leitura crítica de quem vivencia tais conflitos na sua trajetória de vida tanto pessoal quanto coletiva, inclusive no meio acadêmico e profissional.

Certamente, "equilibrar-se no fio da navalha" traz múltiplas tensões. Apesar de enriquecer e renovar as visões até então apresentadas, o surdo intelectual "ameaça territórios historicamente demarcados", trazendo "elementos novos de análise e novas disputas aos espaços de poder acadêmico", além de ser colocado sob suspeita por aqueles que só acreditam na produção de conhecimento neutro e deslocado dos sujeitos que o produzem, como Gomes (2010, p. 492) nos inspira a pensar.

Nesse sentido, focalizando a intelectualidade negra na academia, Mama (2010, p. 605) relata o descaso da comunidade científica mundial para com as publicaçóes africanas sobre os efeitos nocivos da globalização. Para a autora, deve-se a estudiosos africanos algumas das mais contundentes críticas à globalização e ao imperialismo. Tais críticas, no entanto, são reduzidas no máximo à categoria fútil de "literatura de protesto", pois são completamente ignoradas pelas principais obras editadas pelo mundo sobre a temática. No seu entender, os intelectuais negros africanos produzem uma pesquisa acadêmica que se vê como "parte integrante da luta pela liberdade e que responde, não perante esta ou aquela instituição, regime, classe ou gênero, mas perante a imaginação, as aspiraçóes e os interesses da gente comum".

Mama (2010, p. 605) leva-nos a pensar que uma atitude responsável ética e ativa exige que façamos mais do que nos colocarmos à margem dos problemas sociais. Exige que, enquanto acadêmicos, "ultrapassemos a nossa tradição liberal de neutralidade perante as políticas e que desenvolvamos uma ética mais radical, susceptível de questionar e interpelar ativamente as hegemonias globais". A autora questiona: 
Qual o contributo que a nossa pesquisa e o nosso conhecimento poderá [sic] trazer aos diversos contextos dos povos que estudamos? Como é que a nossas atividades de pesquisa afetam a vida daqueles que estudamos? Será possível desenvolvermos estudos sobre África de maneira a estes mostrarem um maior respeito para com as vidas e as lutas do povo africano e as suas agendas? Será possível promovermos estudos que contribuam para o bem da África? (MAMA, 2010, p. 610).

Nesse quadro, a contribuição social da pesquisa realizada por surdos não pode ser mais clara: primeiramente, como agenda geral, tem a funçáo de ressemantizar o conceito de surdez, politizando e ressignificando a discussão a partir da suplantação da arraigada ideia da deficiência, da menos-valia, da insuficiência. Em segundo lugar, em sintonia com o paradigma de racionalidade científica chamado de emergente (SOUZA, p. 2005), parece esmerar-se para que a prática se adiante à teoria, pois muitas pesquisas trazem para os espaços acadêmicos questóes já debatidas ou vivenciadas em comunidade. Os pesquisadores surdos têm, pois, na academia, o respaldo e a escuta necessários às transformaçôes sociais que necessitam.

A seguir, analisaremos o modo pelo qual o sujeito da pesquisa apresenta (ou omite) a sobreposição de papéis discursivos (entre o fazer acadêmico e o fazer militante) na seçáo introdutória de uma tese de doutorado em Educação. Isso porque, a rigor, na introdução de dissertaçóes e teses, esperase que o sujeito apresente o tema da pesquisa e seu posicionamento sobre ele. $\mathrm{Na}$ análise a seguir, focalizaremos, de maneira especial, como o engajamento do sujeito é apresentado na pesquisa e como (ou se) o sujeito da pesquisa se esquiva de eventuais repercussôes dessa relaçấo sobre o éthos (imagem de si) do pesquisador.

\section{A sobreposiçáo de um fazer acadêmico e de um fazer ativista no fio do discurso}

A tese selecionada para análise (T1) foi defendida em 2010, na Universidade Federal de Santa Catarina (UFSC), no Programa de PósGraduação em Educação. Trata-se de uma tese que analisa o papel do implante coclear na constituiçáo de crianças surdas implantadas. Notadamente, a pesquisa define o implante como uma ameaça ao modo de vida surda, considerando-o uma imposição de famílias que, possívelmente, náo tiveram acesso ao discurso concorente (sobre a Libras). Com o objetivo de flagrar em que medida a relação de engajamento é assumida ou negada 
pela locutora da tese, como essa relação é justificada e quais são as estratégias requisitadas para legitimar a pesquisa no âmbito da academia, analisaremos, a seguir, sequências discursivas representativas dessa relação que constam da seção de introdução da T1, apresentando, antes disso, uma breve descrição da produção:

Título: Implante coclear na constituição dos sujeitos surdos

Autora: Patrícia Luiza Ferreira Rezende

Instituiçáo: Universidade Federal de Santa Catarina

Programa: Programa de Pós-Graduação em Educação

Linha: Sem indicação

Orientadora: Profa. Dra. Ronice Muller de Quadros

Coorientadora: Profa. Dra. Maura C. Lopes

Ano de defesa: 2010

Número de páginas: 164

Objetivo: Problematizar os discursos sobre o implante coclear, produzidos pelas famílias e profissionais da saúde, investigando como tais discursos constituem os surdos.

Corpus: entrevistas com mães (líderes sociais) de crianças implantadas, material midiático e material de eventos sobre o implante coclear.

Estrutura: i) Elementos pré-textuais; ii) Apresentaçãoª ;iii) Capítulo: I: A invenção da surdez pela medicina; iv) Capítulo II: Trilhas investigativas; v) Capítulo III: Estudos Culturais e Estudos Surdos com inspiraçáo pós-estruturalista; vi) Capítulo IV: Discursos enunciados na normalização surda; vii) Findar? Um ato de ousadia; viii) Elementos pós-textuais.

Quadro 1: Caracterização da tese selecionada ${ }^{4}$

Fonte: Elaboração própria

A seção introdutória da T1, intitulada Apresentação: o meu corpo surdo que pulsa, questiona e pensa, constitui-se de uma narrativa subjetiva a partir da qual a locutora apresenta sua história de vida (batalhas e conquistas) e as motivaçóes pessoais para a escolha do tema da pesquisa. Expóe, sem rodeios, a sua relação de militância contra o implante coclear, trazendo à tona conflitos, embates e reflexóes explícitas sobre o entrelaçamento entre pesquisa e militância social, como quando caracteriza a sua atividade de

"Consideramos que a seção intitulada "Apresentaçâo", na T1, cumpre o objetivo e o funcionamento discursivo da seção "Introdução", que está ausente, pelo menos com essa nomeação, na tese em análise. Assim, embora seja possível diferenciar genericamente as seçôes "apresentação" e "introduçáa", sobretudo quando compóem concomitantemente uma dissertação ou tese, em muitas ocasiōes elas são tomadas uma pela outra, como é o caso da T1.

${ }^{3}$ Tese selecionada a partir do corpus constituído em pesquisa anterior (RIBEIRO, 2012). 
pesquisa como "uma militância entremeada na imensidáo da academia, na pesquisa, na produção desta tese” (REZENDE, 2010, p. 40).

Assim, explicita o caráter cindido da locutora da tese, que se apresenta dominado por papéis sociais distintos: um desempenhado pelo sujeito pesquisador - alguém em busca do título de doutor e das demais qualificaçôes vinculadas a ele -, outro pelo sujeito surdo ativista ou militante - alguém que faz parte de uma comunidade com história e cultura específicas e que aceita e assume o papel de lutar por ela. Nas sequências a seguir é possível flagrar momentos em que a relação de engajamento da pesquisa é nitidamente abordada:

(01) Esta tese nasceu das minhas inquietaçôes como militante surda em movimentos e lutas pela causa surda, que questiona os discursos normalizadores em nossos corpos surdos. Essas inquietaçóes sáo viveres e impasses constantes na minha vida e na do povo surdo, são o transcorrer de mares impetuosos e serenos pela vida das nossas mãos, que exaltam a língua de sinais e a cultura surda. Elas representam as nossas resistências surdas (p. 28).

(02) (...) As produçôes, as experiências, as singularidades e as peculiaridades estão neste processo de pesquisa. Assim, a minha história pessoal está sempre intimamente ligada à produçáo desta tese (p. 29)

Em (02), vemos um sujeito militante que se torna pesquisador, não o contrário: é o ser comunitário que funda o ser da pesquisa. Com marcas de enunciação na primeira pessoa (minhas inquietaçôes, nossos corpos surdos, minha história pessoal), as sequências não buscam camuflar o caráter subjetivo e pessoal que os atravessa, tampouco justificar a pesquisa com argumentos preponderantemente acadêmicos: as motivações pessoais (ou comunitárias) sáo explicitadas sem maiores ressalvas, o que pode ser considerado um desvio do padrão de locuçáo e posicionamento esperado, quando se pensa nas normas que regem o discurso acadêmico tradicional.

A partir de uma seleçáo lexical característica de movimentos sociais (luta, resistência, causa, movimento e militante), é possível compreender tais sequências como uma espécie de "discurso-açáo militante" que protesta e resiste à ação de outros discursos, ditos normalizadores, provavelmente advindos de formaçôes discursivas 5 clínicas. "Blindado" pela academia,

${ }^{5}$ A noção de Formação Discursiva (FD) foi primeiramente apresentada por Foucault e, posteriormente, reelaborada por Pêcheux no quadro da Escola Francesa de Análise do Discurso. Comumente, define-se uma FD como o que pode e o que deve ser dito em uma dada conjuntura, determinando, ao mesmo tempo, certa regularidade e certa dispersão de sentidos 
tal contradiscurso retoma, nega e desautoriza outro discurso, a saber, um discurso secular e fortemente protegido pela ciência: o discurso da medicina, representado, no excerto em questão, pelo sintagma discursos normalizadores, que, para a locutora, pretendem "normalizar" os surdos, isto é, diminuir ou acabar com os efeitos ditos nocivos da surdez.

As próximas sequências nos levam a considerar que tal empreitada (articular pesquisa e ativismo social) inclui não apenas o desejo de reordenar as relaçóes de poder entre surdos e ouvintes, mas também o de reconstruir a imagem social dos surdos, como se poderá perceber, através de uma manobra (inter)discursiva, em que as imagens de sujeito pesquisador e de sujeito militante se misturam:

(03) O corpo surdo que pulsa, questiona e pensa. O título desta apresentação condiz com meus sentimentos, minhas pulsaçóes, meus questionamentos, meus pensamentos, meu embate acadêmico e militância. Um corpo pulsante pelos ideais do povo surdo, pela sua história de lutas, batalhas, combates e produçóes culturais. Difícil não tomar posição e partido pelos e com meus pares surdos. São resistências surdas em minha vida, escolhas, renúncias, sentimentos, subjetividades afloradas no meu ser surdo (p. 36).

(04) A escolha deste tema é pessoal e inerente à questão da minha vida, por eu ser uma lutadora do povo surdo e hastear a bandeira da Língua de Sinais e da Cultura Surda, artefatos esses fortemente conectados à minha vida, ao meu coração, à minha alma. Além desses motivos pessoais, também sou movida pelas trilhas acadêmicas e científicas que me impulsionam a fazer pesquisa envolvendo o tema do implante coclear. Estamos vivenciando o auge da ciborguização do humano, o auge das políticas de normalização dos sujeitos, o auge da política de inclusão que parte do imperativo do acesso a todos. Diante desses fatores, nascem inquietaçóes e impulsos para a pesquisa (p. 36).

Nesses excertos, é perceptível a preocupação do sujeito falante em delinear mais a imagem de sua faceta que milita do que a imagem de sua faceta que pesquisa, ainda que esta também esteja presente em, por exemplo,

(PÊCHEUX; FUCHS, 1990). Em estudos recentes, Maingueneau (2006) afirma preferir o termo "posicionamento" a "formação discursiva", defendendo uma relativa proximidade e intercambialidade entre tais noçóes.

${ }^{6}$ Em pesquisa anterior, projetamos o campo discursivo da surdez como constituído por um espaço em que se confrontam duas formaçôes discursivas (FD) - uma clínica, outra linguísticoantropológica. A partir da primeira FD pode-se vislumbrar um discurso de fundamentação ouvintista (DFO), caracterizado pelo princípio de que o surdo é um "ouvinte incompleto", que pode "aperfeiçoar-se" por meio de condutas específicas. A partir da segunda FD origina-se um discurso de fundamentaçáo surda (DFS), que determina uma conduta de vida pautada pela riqueza da "experiência visual", postulando que ser surdo é uma questão vivencial, que se baseia em uma língua e em uma comunidades específicas (RIBEIRO, 2008, p. 58). 
também sou movida pelas trilhas acadêmicas e cientificas que me impulsionam a fazer pesquisa envolvendo o tema do implante coclear (ressaltando o caráter de adicionalidade [secundária] resultante do advérbio também).

Em (03) e em parte de (04), o fazer militante sobrepóe-se definitivamente ao fazer acadêmico, uma vez que é difícil não tomar posição e partido pelos e com meus pares surdos.

Logo, a insistência na filiação social ou militante chama a atenção e sugere, de imediato, alguma relação com o éthos pré-discursivo (AMOSSY, 2005), pois o discurso introdutório irá reelaborar de diferentes maneiras a relaçáo pessoal do sujeito com o tema da pesquisa. Vê-se, por exemplo, que (03) e (04) reelaboram o conteúdo de (01).

A estratégia de reelaboração, entre inúmeras possibilidades, pode ser entendida como indício de ocorrência de relaçóes interdiscursivas que ultrapassam o aqui-agora textual. No presente caso, nós a correlacionamos também (mas não exclusivamente) a preocupaçóes com o éthos prédiscursivo ${ }^{7}$, como foi dito, pois, em termos discursivos, por que a locutora (L) da tese reelaboraria, com insistência, no texto de abertura, informaçóes relativas ao caráter nitidamente pessoal/ativista de sua pesquisa se, de certo ponto de vista, isso poderia desmerecer seu trabalho?

Primeiramente, talvez seja porque existe um desejo forte da parte de L de ver suplantados os procedimentos de exclusão (sobretudo a interdição) discutidos por Foucault $(2006)^{8}$. Nesse sentido, é preciso falar e discutir a atividade ativista na pesquisa, ao invés de ceder à interdição produzida pela tradição. Em segundo lugar, parece haver o esforço de L para determinar, logo de saída, a semântica global que governa sua pesquisa, dando indícios do sistema de restriçóes discursivas que será imposto por ela. Se se trata de

$7 \mathrm{O}$ "éthos", oriundo da retórica aristotélica e (re)utilizado na/pela $\mathrm{AD}$, pode ser definido como a imagem de si que o locutor projeta no discurso. Tal imagem pode ser dividida em éthos prévio (ou pré-discursivo), compondo a imagem que dado locutor evoca antes mesmo de "abrir a boca"; e éthos discursivo, que é construído a partir de um ou mais episódios de fala particulares, delineando tom, caráter e corporalidade. O éthos discursivo pode ser considerado dito (quando se manifesta em palavras que qualificam aquele que fala) ou mostrado (quando tal qualificação se dá por pistas indiretas como o tom e mostras do caráter) (cf. AMOSSY, 2005; MAINGUENEAU, 2008).

${ }^{8} \mathrm{O}$ controle na produçấo do discurso pode ser ilustrado por aquilo que Foucault (2006) chamou de "procedimentos de exclusão". O mais evidente e familiar seria a interdição, seguida da separação e da rejeição. Quanto à interdiçâo, que nos interessa mais perto neste momento, é o caso de se pensar o que a sociedade reconhece como legítimo de ser sustentado por um surdo. Um surdo pode sustentar os saberes sobre o seu grupo? Pode tornar-se um pensador? Criticar a sociedade? 
uma pesquisa com preocupaçóes militantes, certamente restriçóes discursivas específicas lhe serão impostas. Pode-se supor também que, para os objetivos da pesquisa, a inter-relação é vista como altamente contributiva, pelo menos pela comunidade acadêmica à qual o sujeito da pesquisa pertence e se reporta (a comunidade surda, de maneira ampla, ou o movimento surdo, de maneira específica).

Em terceiro lugar, tal estratégia é fruto da instauração de uma cenografia ${ }^{9}$ que é compatível com a semântica global de uma tese que nasce no seio de um movimento social. Os excertos (03) e (04), atravessados por um tom confessional e notadamente subjetivo, não se filiam ao discurso acadêmico-científico prototípico de maneira geral, mas a um fazer acadêmico emergente. A veiculação de emoçóes, o compartilhamento de questóes não acadêmicas e a cenografia de relato íntimo ou confessional parecem construir uma estratégia que legitima (ou, pelo menos, caracteriza e torna coerente) o entrelaçamento entre a academia e o engajamento social, uma vez que não estamos diante de um discurso acadêmico padrão.

Por fim, como dito, é possível ver aí ainda uma determinação do éthos (pré)discursivo, pois sustentar com insistência dada posição (no presente caso, o da relação ativismo social/ academia) sugere: a) que se queira negar uma imagem anteriormente evocada (como a de surdos como seres apáticos, de pouco pulso e expressão); ou b) que se queira confirmar uma imagem anteriormente construída, reafirmando o éthos de liderança de L: a voz que fala é forte, emotiva, autruísta e engajada.

Apesar de as sequências discursivas (03) e (04) pertencerem de maneira ampla à elaboração de um contradiscurso, elas não nos parecem de imediato dotadas de preocupaçôes visivelmente contra-argumentativas. Pelo contrário, parecem-nos anseios afirmativos, ou melhor, confirmativos, o que nos leva a relativizar, por ora, a opção "a”, relativa à negação de uma imagem prévia. Com isso, acreditamos que os excertos (03) e (04) buscam confirmar o ethos pré-discursivo de sua fiadora, a saber, o de líder forte e militante ardorosa do movimento surdo, o que pode ser confirmado por sua participação em inúmeras manifestaçóes do movimento surdo. Obviamente, a confirmação desse ethos pré-discursivo se mostra possível apenas para

\footnotetext{
${ }^{9}$ Cenografia é uma das três cenas que compóem a enunciação. Trata-se da cena com que se confronta o leitor diretamente - o que a distingue da cena englobante (domínio do discurso) e da cena genérica (o gênero do discurso). Não é incomum, por exemplo, vermos anúncio publicitáios com cenografias de conversa íntima ou consulta médica. Nas palavras de Maingueneau (2006, p. 96): "a cenografia não é imposta pelo domínio ou gênero de discurso, mas instituída pelo próprio discurso”.
} 
aqueles que, conhecedores ou interessados no discurso veiculado na T1, também conhecem a atuação social (e discursiva) de $\mathrm{L}$.

Ressaltamos que a produtora da T1 é conhecida na comunidade surda por sua atividade distintiva de militância e liderança, sobretudo à época de elaboraçáo da tese. Era ativa em redes sociais, onde atua em favor do movimento surdo, participando e/ou organizando juntamente com demais surdos acadêmicos manifestos políticos em prol da educaçáo dos surdos brasileiros.

Assim, considerando as especificidades da produção e da temática da tese, há que se levar em conta também a especificidade da audiência visada: o leitor modelo projetado pela T1 é conhecedor do universo surdo (e, portanto, provavelmente, da atuação social e do éthos pré-discursivo do sujeito por trás dela). Se não fosse assim, o engajamento não seria abordado com tamanha positividade. Mais do que isso: os excertos apresentados nos levam a supor que o "mundo ético" evocado pela leitura de T1 é muito mais um "mundo ético comunitário" do que um "mundo ético acadêmico", isto é, as regras que regem a semântica global do discurso da T1 subordinam-se mais ao primeiro que ao segundo mundo.

Neste ponto da discussão, evocamos a posiçâo de Gomes (2010, p. 160), para quem a pesquisa ativista distingue-se, de um ponto de vista positivo, de outras justamente por se tratar de uma questão de vida, não de uma questão de trabalho. A autora relata que no filme Viva Zapata ${ }^{10}$, Emiliano Zapata é um camponês mexicano que luta para reaver as terras das quais ele e os seus foram expulsos. Junta-se, assim, a Francisco Madera, que luta em prol de uma reforma constitucional. No desenrolar do enredo, após uma primeira vitória, Zapata procura Madera e pede a devolução de suas terras, mas recebe a resposta de que, para reavê-las, teria que esperar ser consumada, primeiro, a reforma constitucional. Para a autora, "a cena traduz, de alguma forma, a problemática da pesquisa ativista. Para Madera, a revolução significava a ordem constitucional. Para Zapata, ela significa a devolução das terras ao seu povo" (p. 160). E acrescenta:

Para os intelectuais, os camponeses e seus problemas adquirem sentido em
funçáo da ordem política constitucional. Para os camponeses, a revolução
adquire sentido a partir da devoluçáo de suas terras. Ambos, no entanto,
precisam se aliar entre si para dar voz às respectivas aspiraçóes. É preciso
reconhecer esta tensão na pesquisa ativista para nos darmos conta dos

10Produzido por Elia Hazan, em 1952, com Marlon Brando representando Emiliano Zapata (GOMES, 2010). 
âmbitos e dos limites conferidos a tal pesquisa nos espaços institucionais das universidades e das organizaçóes de pesquisa. Para os pesquisadores acadêmicos, o ponto de partida é o mundo "lá fora" com seus problemas, a espera que a atividade de pesquisa por aqueles desenvolvida os venha solucionar. Para o povo em geral, o problema é a "nossa terra" e a "nossa gente" (GOMES, 2010, p. 160).

Ora, a "nossa gente" da pesquisa da T1 espera que os seus corajosos e revolucionários Zapatas conquistem o direito dos surdos quererem ser surdos, que é um motivo de orgulho para o segmento engajado das comunidades surdas. $\mathrm{O}$ mundo da pesquisa, a partir da visão externa, por vezes procura salvar aquele povo do silêncio/apagamento, enquanto o próprio povo espera ver devolvido o seu direito de questionar uma norma ouvintista e de utilizar a língua que lhe apetece.

Além do embate pesquisa/ativismo, percebe-se, nos excertos destacados de T1, uma tensão constitutiva entre a esfera do individual e a do coletivo. Essa tensão pode ser percebida pelo menos por duas vertentes: a primeira é determinada pelo sistema pronominal, definindo se o locutor se inclui ou não no corpo social a ser analisado. Nos excertos em tela, vemos movimento nos dois sentidos: ao mesmo tempo em que o sujeito se coloca como parte de uma coletividade (nossos corpos surdos), faz questão de preservar a sua face individual (por eu ser uma lutadora).

A segunda é determinada pela distinção do ser no seio de sua coletividade, como no caso já analisado, em que se pôde perceber a preocupação de L em definir-se individualmente como sujeito engajado e militante, confirmando o seu éthos pré-discursivo - engajamento que não é determinado apenas pela surdez do indivíduo, mas por histórias e atributos individuais, uma vez que nem todos os surdos sinalizadores são ativistas, vale lembrar.

Tocando a esfera coletiva, mas partindo de uma abordagem individual, o excerto (03) apresenta ainda outra motivação pré-discursiva, que parte do ponto de vista coletivo, talvez contra-argumentativo, como sugerido na opção "a”, apresentada anteriormente e resgatada agora. Em o corpo surdo que pulsa, questiona e pensa. O título desta apresentação condiz com meus sentimentos, minhas pulsaçōes, meus questionamentos, meus pensamentos, meu embate acadêmico e militância, o lexema corpo surdo é caracterizado pelas figuras pulsa, questiona e pensa. Ora, tal excerto combate um ethos prédiscursivo que teria o corpo surdo como inerte, apático e vazio. Contudo, a imagem prévia combatida não é, especificamente, a do sujeito individual 
(que já deu mostras da confirmação de seu éthos [pré] discursivo de sujeito engajado), mas o estereótipo do sujeito coletivo, ou melhor, do sujeito surdo enquanto coletividade. Assim, nega-se o éthos pré-discursivo coletivo de inércia ou apatia do sujeito que náo ouve, ao mesmo tempo em que se constrói para L (e, por extensão, para os outros surdos) um éthos discursivo de sujeito ativo, capaz e questionador, demonstrando isso náo apenas pelo tom da enunciação (éthos mostrado), mas também pelas informações fornecidas no enunciado (éthos dito).

Em resumo: há aqui, portanto, duas maneiras distintas de $\mathrm{L}$ se relacionar com o éthos pré-discursivo: confirmando dada imagem prévia individual (de militante ardoroso) e negando algum indício de ethos prévio coletivo (do ser surdo como inerte ou incapaz). Como se sabe, o éthos não se mostra como artifício imposto pelo sujeito, mas como adequado a uma dada formação discursiva, com as coerçôes que lhe são próprias (as de sua semântica global).

Pensando agora nas projeçóes do éthos discursivo nos excertos provenientes da T1 (que, como foi visto, corroboram ou negam imagens prévias), consideramos que a voz que neles repercute fala por si (esta tese nasceu de minhas inquietaçóes), mas, ao mesmo tempo, traz à tona as angústias de uma coletividade (o povo surdo). É, ao mesmo tempo, firme e decidida, embora emotiva e ativa, condizente com um corpo que náo se quer sob controle. É adequada a alguém capaz de questionar-se e inquietarse, de pulsar e envolver-se no altruísmo de movimentos de luta em nome de uma coletividade, de onde se pode projetar um éthos de determinação e militância.

Dotada de iniciativa, a voz que ressoa não delega a construção de sua imagem apenas ao éthos mostrado (ao tom que assume, à escolha das palavras, ao acento apreciativo). A imagem da locutora é aqui construída em larga medida pelo viés do éthos dito, pois, fazendo jus a seu éthos de ser capaz de ação e reflexão, a locutora toma as rédeas da produção de sua imagem e se define, no enunciado, como uma lutadora, que pulsa, questiona e pensa, que se preocupa em hastear a bandeira da Lingua de Sinais e da Cultura Surda, pois tem ideais, coração e alma.

Como foi dito, a impressão que temos é a de que a imagem de militante se sobressai à de pesquisadora, nos excertos selecionados da T1. No entanto, em (04), embora determine a relaçáo inerente e necessária entre sua vida e o tema da pesquisa, reivindicando figuras metafísicas como alma e coração, com o intuito de determinar o lugar afetivo dessa relação, L diz 
também, ao mesmo tempo, ser movida pelas trilhas acadêmicas e cientificas que me impulsionam a fazer pesquisa, modalizando, de alguma forma, o caráter militante dos excertos anteriores e demonstrando de maneira clara a presença de motivaçóes acadêmicas. E para adequar a enunciação à sua "nova" posição discursiva (a de sujeito da pesquisa), L conclama agora discursos acadêmicos para compor o seu: a saber, o discurso da biotecnologia (estamos vivenciando o auge da ciborguização do humano), o da antropologia médica (o auge das políticas de normalização dos sujeitos) e das políticas socioeducacionais ( $o$ auge da politica de inclusão), posição adequada ao éthos de um sujeito pesquisador, conhecedor e entendedor de um universo de conhecimento mais amplo, não restrito ao seu próprio tema.

Temos aí o despontar do que Maingueneau (2008) denomina ethos híbrido, conceito que indica uma mistura de éthe: vemos, no discurso da T1, a combinação de traços que relevam tanto de um éthos de pesquisador(a), quanto de um éthos de ativista engajado(a) em dada causa social, com clara prevalência do segundo, pelo menos nos trechos em análise, fato que remete a mundos éticos distintos e náo comumente relacionados. Se ocorrências como as veiculadas (03) e (04) atravessassem em abundância todas as seçôes da tese em análise e se a pesquisa se restringisse a isso, estaríamos diante de um problema de natureza acadêmica, não mais discursiva. Ora, um estudo que se diz partidário, motivado e estritamente engajado talvez imponha problemas perante pelo menos um dos elementos de cientificidade propostos por Eco $(1992)^{11}$.

Contudo, vemos que ocorrências como as das sequências discursivas analisadas aparecem principalmente na seção apresentação (uma seção que, em princípio, permite manifestações mais subjetivas, oriundas de experiências e/ou vivências pessoais, se pensarmos no funcionamento discursivo dessa seção). Nas demais seçôes, no entanto, o texto assume um padrão de elocuçáo bastante diferente, ou seja, mais afeito aos moldes do discurso acadêmico tradicional, apesar de, certamente, ainda guardar traços militantes que lhe são peculiares. Assim, parece haver, da parte de L, um esforço para delimitar a sobreposição de éthe aparentemente conflituosos que se fazem presentes na introduçáo da tese. Em outros capítulos podem ser observadas manobras discursivas que intencionam manter $\mathrm{L}$ distante do ativismo social, ou melhor, que tentam construir barreiras entre o eu-

\footnotetext{
${ }^{11}$ Para Eco (1992), um estudo é científico quando apresenta os seguintes requisitos: a) o estudo focaliza um objeto definido e reconhecível por todos; b) o estudo diz sobre o objeto algo que ainda não foi dito ou revê sob ótica diferente o que já se disse; c) o estudo é útil aos demais; d) o estudo oferece elementos para a verificação e a constataçáo das hipóteses apresentadas.
} 
pesquisador e o eu-militante, como se verá adiante em uma sequência ilustrativa retirada da conclusão da tese.

Mas isso náo seria contraditório? Para que, afinal, assumir o engajamento para depois tentar desvencilhar-se dele? Ora, esse pode ser justamente o argumento de maior valor na tese analisada. $\mathrm{O}$ sujeito pesquisador se coloca como ativista, integrante e conhecedor da realidade a ser analisada, mas, ao mesmo tempo, como um pesquisador que internalizou as regras do jogo, isto é, como um acadêmico capaz de controlar e vigiar o seu distanciamento/proximidade em relação a seu objeto de pesquisa, conforme lhe convenha, como atestam as sequências discursivas a seguir, retiradas do capítulo de conclusão da tese ${ }^{12}$ :

(05) Foram muitos os momentos em que precisei fugir da militância, emergir dos "mergulhos militantes" da causa e dos movimentos surdos, para poder dialogar com Foucault, que pede o distanciamento da militância no mergulho das problematizaçōes que fiz ao longo desta tese. Foram momentos sofridos. Muitas palavras e pensamentos foram apagados das páginas dessa produção por conter conteúdos militantes. Fiz o que era possível para analisar, problematizar e dialogar com Foucault. Ele me fez entender que, mesmo estando enredada pelas práticas sociais e jogos de poder/saber e imersa nos muitos discursos e saberes da norma ouvinte e da norma surda, eu posso me vigiar e ser um sujeito que olha e diagnostica as práticas do seu tempo e espaço. O tempo e o espaço do mundo surdo.

(...) Travei, no meu interior, um forte embate, pois, a todo tempo, precisei fugir das armadilhas impostas pela militância. Foi uma vigilância constante para não cair no abismo teórico de uma tese.

(...) Cada discurso produzido me doía o coração, a minha alma surda. Eu não podia me sobressair na militância surda. Vivo em constante vigilância para não cair no abismo dessa militância: é preciso viver o auge das teorizaçóes foucaultianas. Foucault foi o meu companheiro nesta jornada de pesquisa na selva amazônica, uma viagem gratificante, apesar dos percalços e entraves. Mas cheguei aqui! O final de uma jornada e o começo de outras. São os inícios e os finais das jornadas da minha vida (p. 157).

Como se vê, embora a relação de ativismo seja claramente manifestada na apresentação da pesquisa, na conclusão há empreendimentos que visam reforçar o éthos do sujeito de pesquisa, demonstrando que ele manteve sob

\footnotetext{
${ }^{12}$ Embora este artigo se limite a analisar a sobreposição de papéis discursivos na seçấo introdutória da tese, selecionamos em (05) sequências discursivas provenientes da seção conclusiva, com o intuito de ilustrar a ocorrência de um fenômeno distinto que lança luzes sobre nossa discussão. Logo, não é nosso objetivo analisar a conclusão da tese, mas tão somente pinçar dela sequências discursivas capazes de subsidiar nossas reflexóes, como se verá adiante.
} 
vigilância constante o sujeito militante, não apenas fugindo dele, como também apagando as suas marcas, quando ele insistia em se manifestar (Muitas palavras e pensamentos foram apagados das páginas dessa produção por conter conteúdos militantes).

Em termos de éthos, constrói-se, nesses excertos, a imagem de uma pesquisadora consciente e com poder de discernimento, capaz dessa vigília. $\mathrm{E}$, se conteúdos militantes foram apagados, presume-se então que eles não existam mais, ou, pelo menos, que foram reduzidos a certa insignificância. Por esse viés, consideramos que explicitar, no nível do enunciado, a existência da relação de militância, pode não ser o mesmo que praticá-la na pesquisa. Em outras palavras: apesar de mencionar seu engajamento no movimento surdo na apresentaçáo da tese, o sujeito sugere ser possível não praticá-lo no desenrolar de sua pesquisa. De maneira semelhante, sustentar no enunciado tal vigília não é o mesmo que praticá-la. O que importa, contudo, em termos discursivos, é a intencionalidade de $\mathrm{L}$ ao enunciar essas questôes. Aqui, a intenção de L, ao que tudo indica, é guiada por uma atitude protecionista da imagem de si enquanto pesquisadora, assim como da sua pesquisa enquanto produção de uma cientificidade, pois prevê a repercussão (com avaliação imprevisível) de sua pesquisa: o meu discurso será examinado, questionado, debatido e até mesmo impugnado, pois é a produção de uma verdade, de uma cientificidade, de uma prática discursiva, de um embate contra a medicalização do ser surdo (p. 40).

Manter o sujeito que milita "trancafiado" não é, todavia, uma atividade fácil ou natural ao sujeito, afinal, vemos em (05), no capítulo de conclusão da tese, que foram momentos avaliados como sofridos, embora certamente determinantes para se jogar com destreza o jogo da academia. Foucault aparece como argumento de autoridade e validação dessa prática. É como se L dissesse, "não sou eu quem diz que é possível vigiar e fugir da militância, mas um autor como Michel Foucault". E a atividade de vigília, ainda dirá L, não é exclusiva às searas da militância; afinal, foi preciso também uma vigília constante para não cair no abismo teórico de uma tese - posição que corrobora o éthos de uma pesquisadora consciente de seu processo de pesquisa.

Tal expertise, atribuída ao sujeito pesquisador, aparece em outros momentos da tese como um processo de aquisição de habilidades e de amadurecimento propiciados pela atividade de pesquisa atual, afinal, foram necessários exercícios de autocontrole para prover o entendimento das distinçóes entre ser surda e ser pesquisadora - distinção certamente percebida a partir da pesquisa em análise, não anteriormente, visto que a autora/locutora da T1 
não cursou mestrado, tendo ido diretamente para o doutorado. O fato de tal vigília e autocontrole não serem nem passe de mágica nem algo facilmente praticado faz com que o nível de dificuldade ressoe (positivamente) nas qualidades de $\mathrm{L}$ enquanto pesquisadora, impactando diretamente na imagem do sujeito da pesquisa.

\section{Palavras finais}

A pesquisa acadêmica empreendida por surdos pode ser considerada uma amostra significativa do paradigma de racionalidade científica emergente de que nos fala Santos (2005). Por meio dela, assistimos à ascensão de um povo minoritário que, aos poucos, se desvencilha dos procedimentos de exclusão que o estigmatizava como pária social. Consideramos, portanto, a entrada de surdos na pós-graduação stricto sensu como uma empreitada de resistência social que estabelece um contra-controle e uma nova forçacontrole. Tal movimento é deflagrado por contradiscursos produzidos e apresentados como cientificidades: falamos aqui de uma pesquisa acadêmica que, ao mesmo tempo em que reivindica um lugar nas práticas acadêmicas correntes, constrói para si um lugar político e identitário singularizado, que tanto parte de quanto chega a um meio social determinado.

Por fim, com este artigo esperamos ter demonstrado que a sobreposição entre sujeito e objeto da pesquisa resulta em arranjos discursivos que, por um lado, constroem o éthos da locutora como militante ardorosa, mas, por outro, também como uma pesquisadora conscienciosa, revelando tensóes constitutivas derivadas da necessidade de articular lócus de leitura distintos (a universidade e o movimento surdo), em um esforço para promover transformação de vidas por meio da realização de pesquisa acadêmica.

\section{Referências}

AMOSSY, R. Introdução. In: AMOSSY, R. (org.). Imagens de si no discurso. A construção do ethos. São Paulo: Contexto, 2005. p. 9-28.

DELEUZE, Gilles. Diferença e repetiçáo. São Paulo: Graal, 2006.

DUCROT, O. O dizer e o dito. Campinas, SP: Pontes, 1987.

FOUCAULT, M. Microfisica do poder. Rio de Janeiro: Graal, 2004.

GOMES, N. Intelectuais negros e a produção de conhecimento: algumas 
reflexôes sobre a realidade brasileira. In: SANTOS, B. S.; MENEZES, M. P. (org.). Epistemologias do Sul. São Paulo: Cortez, 2010. p. 492-518.

MAINGUENEAU, D. Gênese dos discursos. São Paulo: Criar Ediçôes, 2005.

A propósito do ethos. In: MOTTA, A. R.; SALGADO, L. (orgs.). Ethos discursivo. São Paulo, Contexto, 2008. p. 11-29.

. Unidades Tópicas e não-tópicas. In: POSSENTI, S; SOUZA-E-SILVA, M. C. P (orgs). Cenas da Enunciaçáa. Curitiba: Criar Edições, 2006. p. 09-24.

MAMA, A. Será ético estudar a África? Considerações preliminares sobre pesquisa acadêmica e liberdade. In: SANTOS, B. S.; MENEZES, M. P. (org.). Epistemologias do Sul. São Paulo: Cortez, 2010. p. 603-37.

MILLS, C. W. Sobre o artesanato intelectual e outras histórias. Rio de Janeiro: Zahar, 1998.

PÊCHEUX, M.; FUCHS, C. A propósito da análise automática do discurso: atualizaçấo e perspectivas. In: GADET, F.; HAK, T. (orgs.). Por uma introdução à obra de Michel Pêcheux: uma introdução à obra de Pêcheux. Campinas, SP: Ed. Unicamp, 1990. p. 163-252.

PERLIN, G. T. Identidades surdas. In: SKLIAR, C. (org.) A surdez: um olhar sobre as diferenças. Porto Alegre: Mediação, 1998. p. 52-73.

RANGEL, M. A Diversidade e a Reivindicação de direitos nos Movimentos Sociais. Revista da FAEEBA - Educaçáo e Contemporaneidade, Salvador, v. 19, n. 34, p. 39-47, jul./dez. 2010. Disponível em: <http://www.uneb. br/revistadafaeeba/files/2011/05/numero34 .pdf>. Acesso: 15 jul. de 2012.

REZENDE, P. L. F. Implante Coclear na constituiçáo dos sujeitos surdos. 2010. 164 f. Tese (Doutorado em Educação). Faculdade de Educação. Universidade Federal de Santa Catarina, Florianópolis, 2010. Disponível em: $<$ http://repositorio.ufsc.br/bitstream/handle/123456789/8545/281476. pdf?sequence $=1>$. Acesso em: 15 jan. 2020.

REZENDE, P. L. F; REZENDE JR, F. F. Os surdos nos rastros da sua intelectualidade específica. In: QUADROS, R. M.; PERLIN, G. (org.). Estudos Surdos. Petrópolis, RJ: Arara Azul, 2007. v. II, p. 190-211. Disponível em: <http://editora-arara-azul.com.br/ParteB.pdf>. Acesso em: 12 mar. 2012.

RIBEIRO, M. C. M. A. A escrita de si: discursos sobre o ser surdo e a surdez. 2008. 207 f. (Dissertação - Mestrado em Estudos Linguísticos) - Fac- 
uldade de Letras, Universidade Federal de Minas Gerais, Belo Horizonte, 2008 .

. O discurso acadêmico-científico produzido por surdos: entre o fazer acadêmico e o fazer militante. 2012. 262 f. Tese (Doutorado em Estudos Linguísticos). Faculdade de Letras. Universidade Federal de Minas Gerais, Belo Horizonte, 2012.

SANTOS, B. de S. Um discurso sobre as ciências. Porto: Afrontamento, 2005.

. Conhecimento prudente para uma vida decente. Introducao. In: . (Org).Conhecimento prudente para uma vida decente. São Paulo: Cortez, 2009

STROBEL, Karin Lílian. Surdos: vestígios culturais não registrados na história. 2008. 176 f. Tese (Doutorado em Educação). Faculdade de Educação. Universidade Federal de Santa Catarina,Florianópolis, 2006.

Disponível em: <http://www.ronice.cce.prof.ufsc.br/index arquivos/Documentos/karinstrobel.pdf $>$. Acesso em: 10 maio 2012. 